Article

\title{
Study on Traffic Conflict Prediction Model of Closed Lanes on the Outside of Expressway
}

\author{
Huimin Ge* ${ }^{*}$, Mingyue Huang, Ying Lu $₫$ and Yousen Yang \\ School of Automobile and Traffic Engineering, Jiangsu University, Zhenjiang 212013, China; \\ 2221804040@stmail.ujs.edu.cn (M.H.); luying@ujs.edu.cn (Y.L.); 2221704040@stmal.ujs.cn (Y.Y.) \\ * Correspondence: hmge@ujs.edu.cn; Tel.: +86-1385-290-8697
}

Received: 11 April 2020; Accepted: 25 May 2020; Published: 2 June 2020

check for updates

\begin{abstract}
Due to the randomness and weak symmetry of traffic accidents occurring in the expressway maintenance operation area, it is difficult to use the number of traffic accidents to evaluate the safety of maintenance operation areas. In this paper, the traffic characteristics and traffic conflicts of the maintenance operation area with the lane closed on the outside of the two-way four-lane expressway are studied. By using the statistical method, the distribution of vehicle speed and time headway in different areas of the maintenance operation area are analyzed, and the queuing characteristics of vehicles in the upstream transition zone of the expressway are determined. Based on improved time to collision (TTC) model, the traffic conflict severity of expressway maintenance operation area is divided. The negative binomial distribution is used to establish a traffic conflict prediction model for the enclosed maintenance area of the outer lane of the expressway, and the validity of the traffic conflict prediction model is verified based on the average absolute error percentage (MAPE). The research results show that: when the $0<$ TTC $<1.3 \mathrm{~s}$, the traffic conflict is serious conflict; when $1.3 \mathrm{~s}<\mathrm{TTC}$, the traffic conflict is non-serious conflict. Furthermore, the traffic conflict prediction model has high accuracy, the MAPE of the warning area and the upstream transition area are $10.8 \%$ and $5.0 \%$, respectively.
\end{abstract}

Keywords: expressway maintenance operation area; traffic characteristics; time to conflict; traffic conflict prediction model

\section{Introduction}

During the expressway maintenance operation area, due to the need to close the lane, vehicles through the maintenance operation area are forced to slow down, lane change, confluence. It not only leads to the increase of traffic conflicts, but also induces traffic accidents, which greatly affects the safety of expressway maintenance operation area. According to China's road safety accident report [1], traffic accidents on expressways accounted for $3.15 \%$ of the total traffic accidents in 2018, and a total of 1100 people were killed in expressway maintenance operation area. In addition, the death rate in China's expressway maintenance operation areas is three times of other regions [2]. Relevant studies show that [3-5], compared with the road sections in the non-maintenance operation area, the traffic accident rate in the maintenance operation area has increased. This increase is mainly due to the complex traffic environment in the expressway maintenance operation area, which leads to more traffic conflicts. Therefore, it is of great significance to study the closed maintenance operation area of the outer lane of the expressway to improve the safety of the maintenance operation area.

Traffic conflict has been widely used as an alternative indicator of traffic accidents [6,7]. The observation time of traffic conflicts is short, and there is a stable correlation with traffic accidents $[8,9]$, which can effectively reflect the safety level of traffic facilities. At present, there are a large number of traffic accident data accumulation in maintenance areas abroad, which are used for traffic safety 
evaluation. Eustace et al. used four years of traffic accident data to construct a negative binomial distribution model for evaluating the safety of the work area [10]. However, there is a general lack of traffic accident accumulation data onto maintenance operation areas in China, and the use of traffic accident data cannot effectively evaluate the traffic safety in expressway maintenance operation areas [11]. Therefore, this paper takes the closed maintenance operation area of the outer of the expressway as the research object, and analyzes the traffic characteristics and the severity of traffic conflicts in the maintenance operation area. Based on the improved time to collision (TTC) model, the severity of traffic conflicts is determined. The negative binomial distribution is used to establish the traffic conflict prediction model, and the effectiveness of the traffic conflict prediction model is verified based on average absolute error percentage (MAPE).

\section{Literature Review}

At present, many studies have been carried out on the safety of the expressway maintenance operation area [11,12], and various management measures have been proposed to improve the safety of the expressway maintenance operation area [13-15]. Garber [16] studied the characteristics of traffic accidents in the maintenance operation area, and the research results showed that compared with the non-maintenance operation area, the proportion of traffic accidents in the maintenance operation area was relatively high. Meng [17] evaluated the collision risk in the maintenance operation area and found that with the increase of traffic volume and the proportion of large cars, the risk in the maintenance operation area also increased. In addition, Wong et al. [18] studied the traffic accidents in the maintenance operation area of California, and the results showed that the severity of the traffic accident was related to the location of the accident, the duration of the operation area and the maintenance type. Generally, the factors affecting the safety of maintenance operation area are related to driving behavior, operation area characteristics, traffic composition and speed limit. Garber and Zhao [16] found that high speed difference and high speed variance were the main causes of traffic accidents. Khattak and Council [19] analyzed the influencing factors of collision frequency in maintenance operation area through historical data, and found that traffic volume is an important factor affecting collision frequency. Venugopal and Tarko [3] used the negative binomial model to study the relationship between collision frequency, traffic behavior and maintenance operation area. The results show that the traffic volume and the length of the maintenance operation area have significant effects on the collision frequency.

In addition, the study of traffic conflict model in expressway maintenance operation area is still at the beginning stage, and the related research is limited to simple linear regression and generalized linear regression. Because the parameters of linear regression obey normal distribution, and the traffic conflict is random and discrete. Therefore, linear regression fitting may lead to errors in the results. El-Basyouny et al. [20] used Poisson distribution model to predict the frequency of traffic conflicts. Sacchi [21] built a relationship model between traffic flow and traffic conflict based on Poisson distribution. However, the Poisson distribution model does not consider the impact of different traffic flows on traffic conflicts, which may lead to errors in the fitting. Zhang et al. [22] and Guo et al. [23] used the traffic conflict model of negative binomial distribution model of random parameters to analyze the safety influencing factors of left-turn and right-turn traffic facilities and large vehicle ratio on traffic conflict, so as to improve the safety of maintenance operation. Yunwen Cai [24] et al. uses traffic conflict technology to analyze traffic conflict, and uses negative binomial distribution and Poisson distribution to build traffic conflict prediction model of single lane ramp and two lane ramp, which verifies that traffic conflict prediction model can effectively evaluate traffic safety. Jia Yong [25] et al. analyzed the relationship between traffic conflict and traffic volume, average speed and vehicle type ratio by using the improved time difference of conflict (TDTC) model and vehicle recognition technology. The results show that the number of traffic conflicts is consistent with the negative binomial distribution.

Most of the previous studies have analyzed the safety factors affecting the expressway maintenance operation area, and the research on the traffic safety evaluation of the expressway outer lane closed 
maintenance operation area is limited. Due to the closed lane outside the maintenance operation area, vehicles need to change lanes freely and forcibly in the maintenance operation area, which will cause interference to traffic flow and easily lead to traffic accidents. Meanwhile, China generally lacks statistical analysis of traffic accident data in maintenance operation area, and it has not been possible to use traffic accident numbers to effectively study traffic safety in maintenance operation areas. Therefore, the purpose of this paper is to establish a traffic conflict prediction model for expressway maintenance operation areas based on negative binomial distribution, and then provide a basis for traffic safety evaluation.

\section{Data Collection and Method}

\subsection{Data Collection}

The Hu-Shan expressway is called Shanghai-Xi'an expressway, with a total length of $1490 \mathrm{~km}$. The Hu-Shan expressway maintenance operation areas studied in this paper belongs to Anhui section. The section is a two-way four lane expressway with a total length of $82 \mathrm{~km}$, a design speed of $100 \mathrm{~km} / \mathrm{h}$ and a lane width of $3.75 \mathrm{~m}$, as shown in Figure 1. Among them, the type of maintenance operation area is the closed outer lane.



Figure 1. Hu-Shan expressway.

Under the "Safety Work Rules for Highway Maintenance (JTG H30-2015)", the maintenance area is divided into six regions, namely Warning Area, Upstream Transition Area, Buffer Area, Activity Area, Downstream Transition Area and Termination Area. Through the field investigation to the maintenance operation area of Hu-Shan Expressway in Lu'an City, Anhui Province, the survey parameters include traffic volume, location speed, time headway and vehicle queue length. Obtain traffic data for $5 \mathrm{~h}$ continuously on each operation area. Among them, the length of the warning area, upstream transition area, buffer area, downstream transition area and termination area is $2000 \mathrm{~m}, 120 \mathrm{~m}, 80 \mathrm{~m}, 30 \mathrm{~m}, 30 \mathrm{~m}$, the length of the activity area is $2 \mathrm{~km}$; the acquisition single stage speed limit is $60 \mathrm{~km} / \mathrm{h}$. The survey Sites 1 and 2 are located in warning area (divided into 2 sections according to the actual speed limit conditions; Warning Area 1 is located in front of the speed limit sign and is $1300 \mathrm{~m}$ away from the upstream transition area; Warning Area 2 is located after the speed limit sign and is $300 \mathrm{~m}$ away from the upstream transition area); Survey Sites 3, 4 and 5 are located in 1/2 of the upstream transition zone, buffer zone and operation zone respectively. By using WM-JD2.0 multi-functional traffic speedometer (Beijing Dafang Technology Co., Ltd. Beijing, China), WM-JD3.0 portable laser measuring instrument (Beijing Dafang Technology Co., Ltd. Beijing, China) and high-definition camera (Hangzhou Lai Lai Technology Co., Ltd. Hangzhou, China), the traffic parameters of the maintenance operation area of Hu-Shan expressway in Lu'an city, Anhui province were collected. The closed form of the lanes and the survey site layout of the maintenance operation area of the Hu-Shan expressway in Lu'an city are shown in Figure 2. 


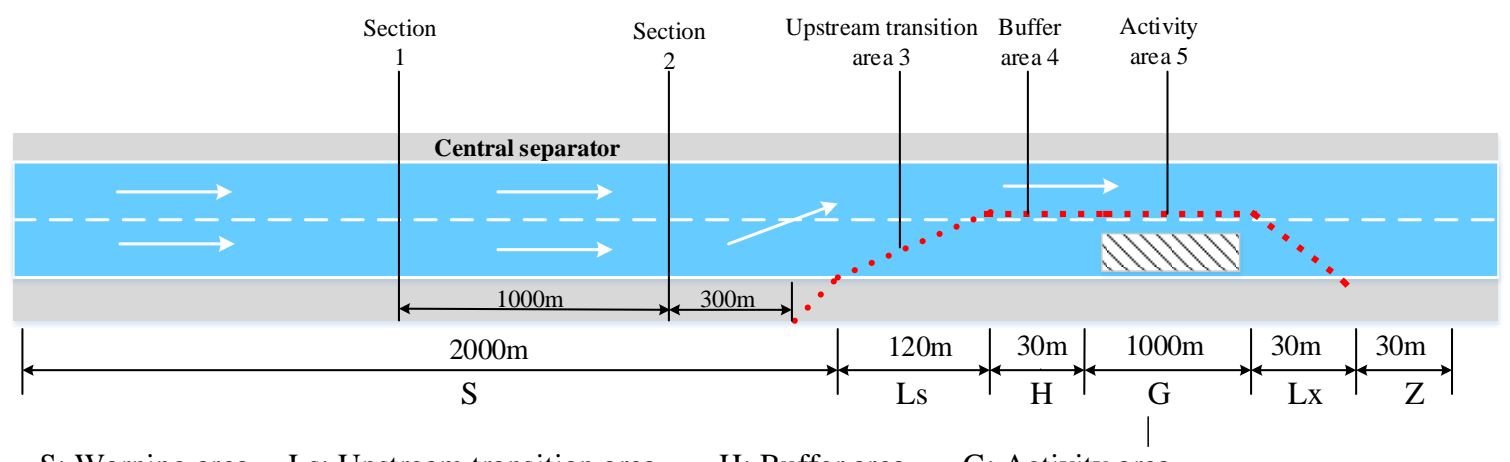
S: Warning area
Ls: Upstream transition area
H: Buffer area
G: Activity area

Lx: Downstream transition area Z: Termination area

Figure 2. Layout of expressway maintenance operation area.

\subsection{Method}

The TTC model is one of the most commonly used measures of traffic conflict time, which refers to the time needed for a vehicle to have a traffic conflict if two cars continue to drive in the same lane at the current speed [26]. The size of the TTC can directly reflect the traffic conflict the probability of occurrence. Among them, the smaller the TTC, the greater the possibility of a traffic conflict. The vehicle trajectory of the process from the occurrence of traffic conflict with the adoption of hedging measures is shown in Figure 3.

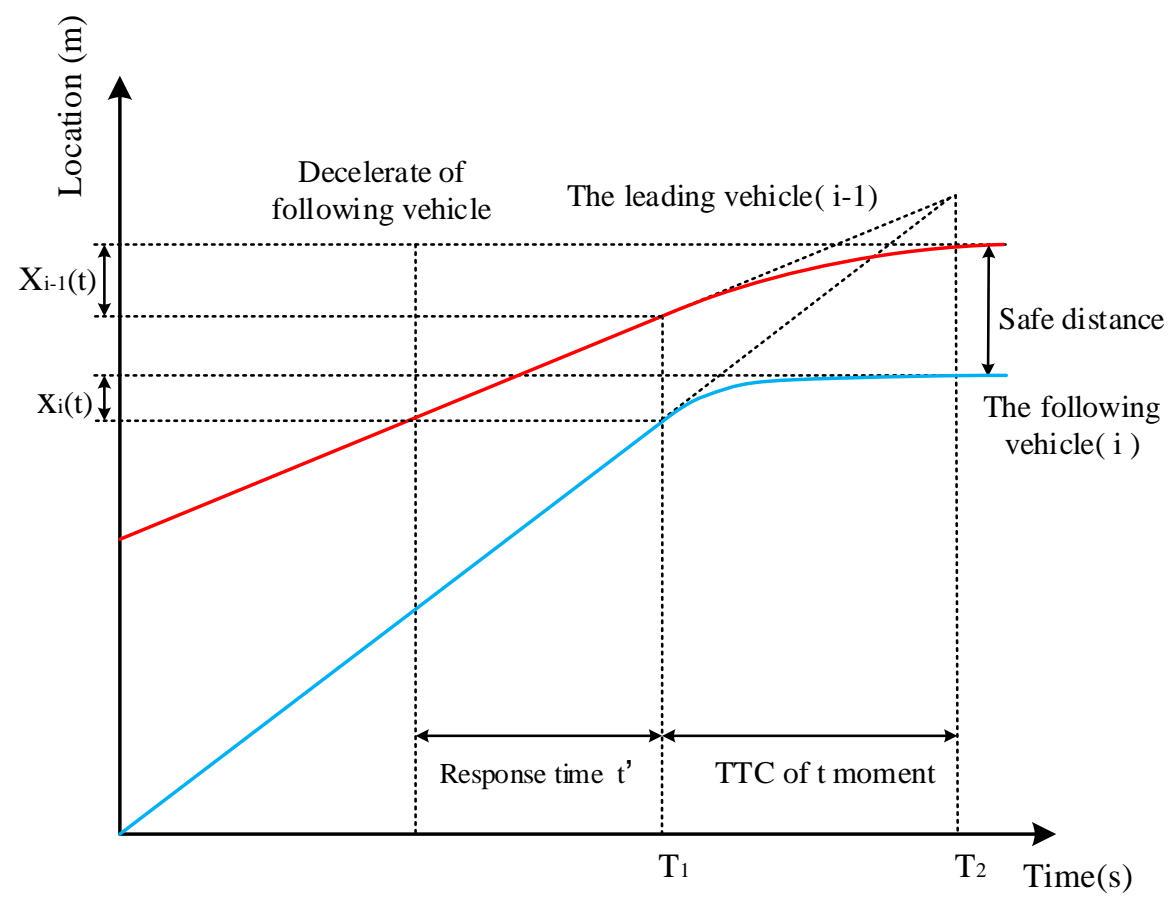

Figure 3. Vehicle trajectory based on time to collision (TTC).

In Figure 3, if the following vehicle speed is greater than the leading vehicle speed, when the following vehicle is in $t_{1}$ moment it is always found that the distance from the leading vehicle is getting smaller and smaller. If no hedging measures are taken, the vehicle will have traffic conflicts occur in $t_{2}$ moment; if the following vehicle adopts risk-avoidance measures, the two vehicles continue to drive at a certain safe distance, the reaction time of the driver of the following vehicle is $t^{\prime}$, and the calculation formula of TTC is as follows:

$$
\mathrm{TTC}_{i}=t_{2}-t_{1}
$$


When calculating the TTC, considering the length of the vehicle, the calculation formula is:

$$
\operatorname{TTC}_{i}=\frac{x_{i-1}(t)-x_{i}(t)-l_{i-1}}{v_{i}(t)-v_{i-1}(t)} v_{i}(t)>v_{i-1}(t)
$$

where: $T T C_{i}$ is the time (s) that the $i$ vehicle with vehicle $i-1$ at which the vehicle had a traffic conflict; $x_{i}(t)$ is the location of the vehicle $i$ and vehicle $i-1$ in moment $t ; l_{i-1}$ is the length of the $i-1$ vehicle $(\mathrm{m}) ; v_{i}(t)$ and $v_{i-1}(t)$ are the speed of the vehicle $i$ and $i-1$ in moment $t$.

Since the observed vehicles are in motion, it is difficult to accurately obtain the position of the vehicle, that is, it is difficult to calculate the space headway $d_{i}$. Therefore, by determining the relationship between the time headway $h_{t}$ and space headway $d_{i}$, the calculation formula of TTC is improved by replacing time headway with space headway. The calculation formula is as follows:

$$
\begin{gathered}
d_{i}=x_{i-1}(t)-x_{i}(t)=v_{i}(t) h_{t} \\
\operatorname{TTC}_{i}=\frac{v_{i}(t) h_{t}-l_{i-1}}{v_{i}(t)-v_{i-1}(t)}
\end{gathered}
$$

where: $d_{i}$ is the space headway of the leading and following vehicles; $h_{t}$ is the time headway of the leading and following vehicles.

\section{Traffic Characteristic Analysis}

\subsection{Traffic Volume Characteristics}

Based on the field investigation of traffic flow in the maintenance operation area of Hu-Shan Expressway, this paper analyzes the traffic volume in the warning area, the upstream transition area and the activity area, as shown in Figure 4. According to Figure 4, it can be found that at 13:00-13:30, the traffic volume in the upstream transition area and activity area reaches the maximum; at 14:30-15:00, the traffic volume in the warning area reaches the maximum; at 12:00-12:30, the traffic volume in the warning area, upstream transition area and activity area reaches the minimum. It can be seen from Figure 3 that when the traffic volume in the warning area increases, the traffic volume in the upstream transition area and the operation area decreases. This is mainly because the traffic volume is greater than the road capacity, forming traffic congestion in the upstream transition area, reducing the speed of vehicles. In addition, from 14:00 to 15:00, the traffic volume in the upstream transition area and operation area increases as the traffic volume in the warning area increases. This may be due to the gradual dissipation of traffic congestion, the decrease in traffic density, the increase in vehicle speed, and the increase in vehicles passing through the survey site.

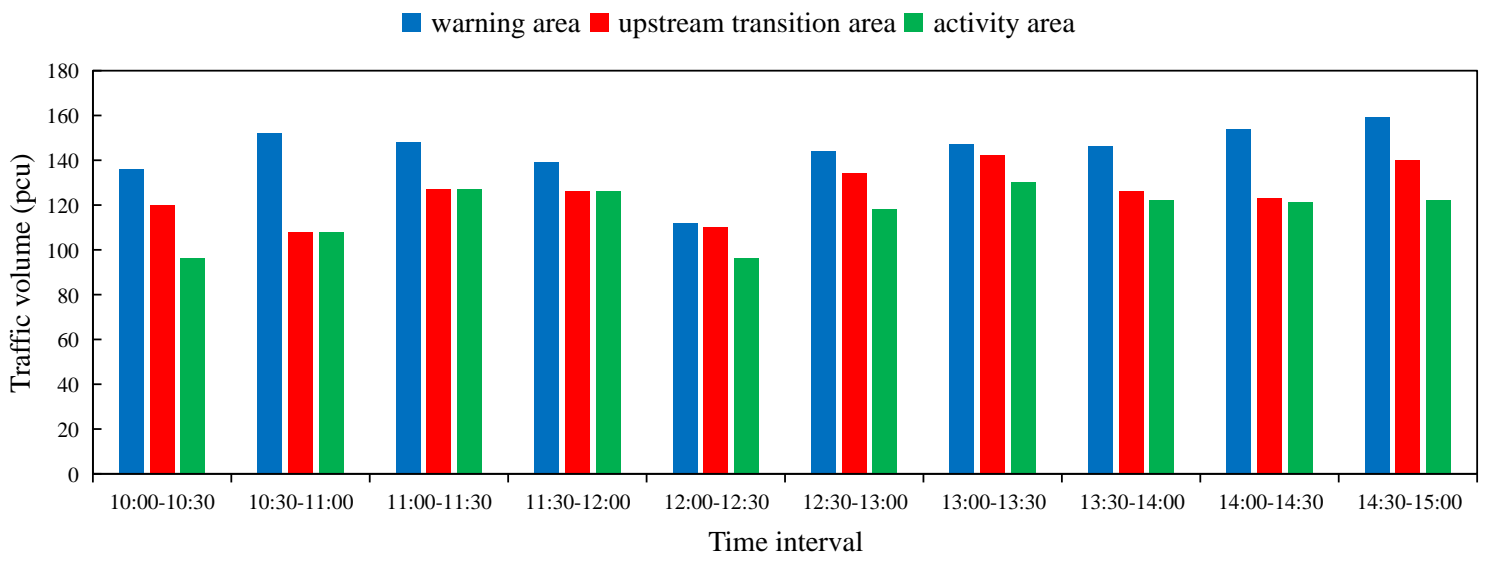

Figure 4. Traffic volume in warning area, upstream transition area and activity area of expressway maintenance operation area. 


\subsection{Speed Distribution}

Speed distribution of vehicle speed at five survey locations in the warning area of the expressway maintenance work area (Warning Area 1), the end of the warning area (Warning Area 2), the upstream transition area, the buffer area and the activity area, and specific statistical results are shown in Table 1. Through the statistical analysis of the speed data, it is found that the vehicle speed decreases gradually from the warning area to the buffer area, which is mainly because the vehicles from the upstream transition area to the buffer area need to merge, resulting in the interruption of traffic flow. However, when passing through the activity area, the speed increases gradually. This is because the vehicle has formed a continuous traffic flow in the activity area, and the vehicle has passed the maintenance operation area to restore normal traffic conditions. The normal distribution function is used to fit the vehicle speeds in different regions, as shown in Figure 5. The results show that the speed distribution in different regions follows a normal distribution, and the $\mathrm{R}$ values are $0.92,0.955,0.978,0.977$ and 0.9017 , respectively.



(a)

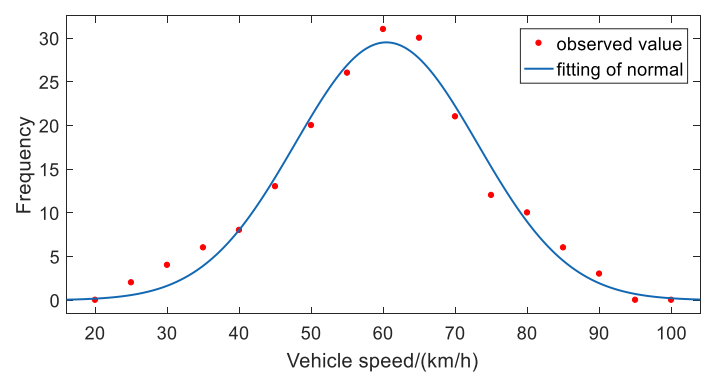

(c)

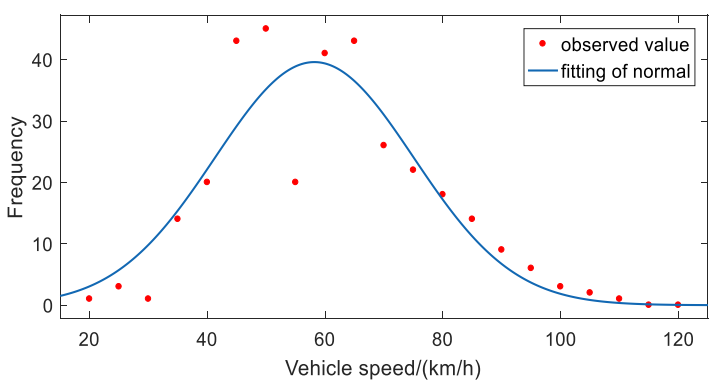

(e)

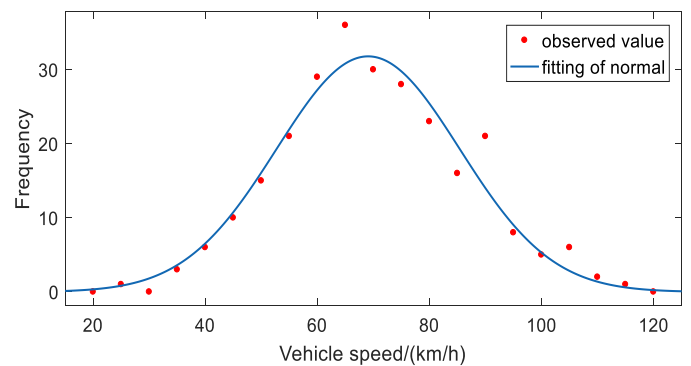

(b)

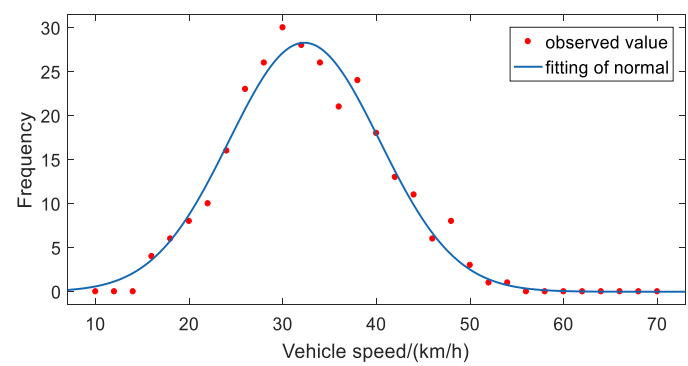

(d)

Figure 5. Distribution of speed in each area of expressway maintenance operation area. (a) Warning Area 1; (b) Warning Area 2; (c) Upstream Transition Area; (d) Buffer Area; (e) Activity Area.

\subsection{Time Headway}

In traffic flow theory, the commonly used time headway models mainly include: negative exponential distribution model, shifted negative exponential distribution model, the Erlang distribution model, M3 distribution model and fixed-length distribution model. Meng Xianghai [11] used the 
Erlang distribution model to fit the time headway survey data of the upstream transition area, and the research results showed that the time headway of the peak period, the flat peak period and the whole day could be fitted with the Erlang distribution. Therefore, this paper adopts the Erlang distribution model to fit the time headway of each region in the expressway maintenance operation area. The model is expressed as follows:

$$
P\left(h \geq h_{t}\right)=\sum_{i=0}^{r-1} \frac{\left(\lambda h_{t}\right)^{i}}{i !} e^{-\lambda h_{t}}
$$

where: $r$ is the order of the Erlang distribution function; the larger the $r$, the more crowded the traffic; $h_{t}$ is the time headway; $\lambda$ is the mean of the distribution function of Erlang; $i=r-1$.

The Erlang distribution function is used to fit the time headway of warning area, upstream transition area, buffer area and activity area, as shown in Figure 6. The results show that the time headway of warning area, upstream transition area, buffer area and activity area all obey the Erlang distribution, where $r=2$. In addition, K-S test and Chi-square test is used to conduct statistical analysis on the time headway of expressway maintenance operation area. The results are shown in Table 2.

Table 1. Statistical Analysis of speed in maintenance operation area.

\begin{tabular}{cccccc}
\hline Statistical Analysis & Warning Area 1 & Warning Area 2 & $\begin{array}{c}\text { Upstream } \\
\text { Transition Area }\end{array}$ & Buffer Area & Activity Area \\
\hline Mean $(\mathrm{km} / \mathrm{h})$ & 90.631 & 68.345 & 60.271 & 36.765 & 60.367 \\
Standard error & 1.274 & 0.946 & 0.690 & 0.460 & 0.940 \\
Standard deviation & 21.9 & 16.3 & 12.1 & 7.8 & 29.5 \\
Sample variance & 487.63 & 274.68 & 328.76 & 380 & 352 \\
Sample capacity & 290 & 320 & 328 & & 29.13 \\
\hline
\end{tabular}

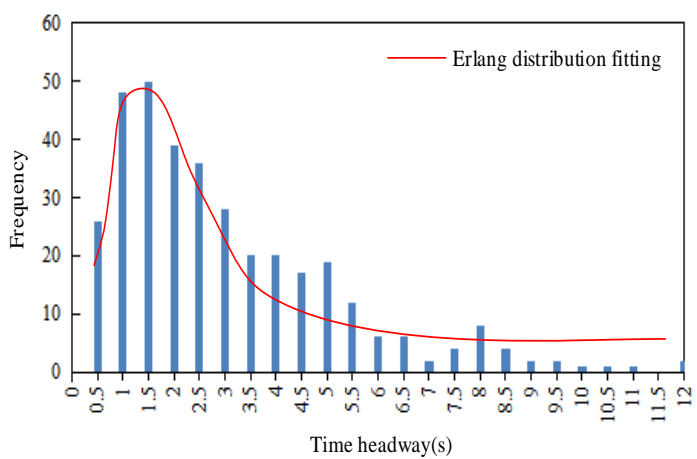

(a)

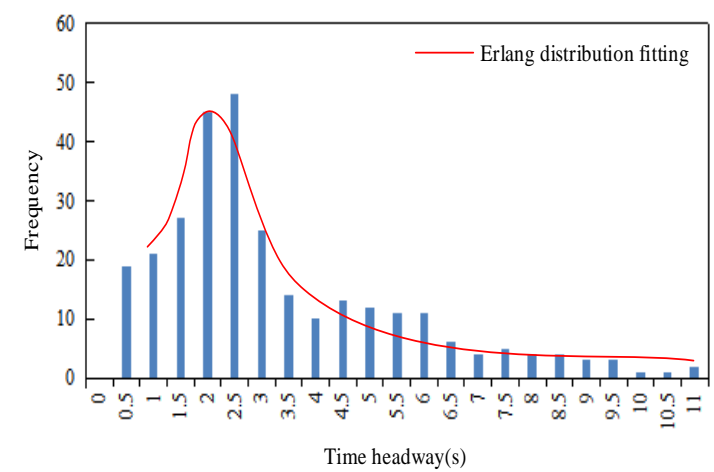

(c)

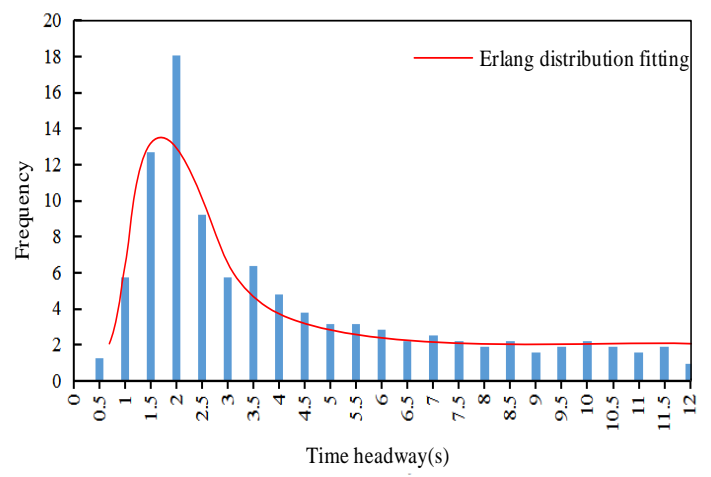

(b)

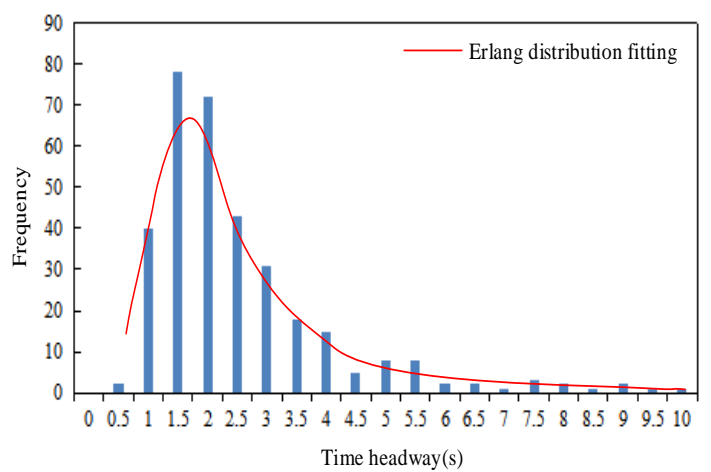

(d)

Figure 6. Time headway distribution in expressway maintenance operation area. (a) Time headway distribution in warning area; (b) time headway distribution in upstream transition area; (c) time headway distribution in buffer area; (d) time headway distribution in activity area. 
Table 2. Statistical analysis of time headway.

\begin{tabular}{ccccccc}
\hline Area & Mean (s) & $\begin{array}{c}\text { Standard } \\
\text { Deviation }\end{array}$ & $\boldsymbol{k}$ & $\begin{array}{c}\text { Sample } \\
\text { Capacity }\end{array}$ & $\chi^{2}$ & Result \\
\hline Warning area & 3.51 & 2.14 & 1.06 & 352 & 29 & Conform \\
Upstream & 4.13 & 2.96 & 1.59 & 302 & 37 & Conform \\
transition area & 3.82 & 2.27 & 1.25 & 289 & 24 & Conform \\
Buffer area & 3.03 & 1.58 & 1.38 & 335 & 22 & Conform \\
Activity area & 3.03 &
\end{tabular}

\subsection{Vehicle Queuing Analysis}

In the upstream transition area, vehicles that normally travel on two lanes need to merge onto one lane and then pass through the expressway maintenance operation area. At this time, traffic congestion delays have formed in the upstream transition area, and vehicles need to slow down and line up through the region enters the activity area. According to the statistical analysis of on-site data, the proportion of queuing length of all vehicles passing through the expressway maintenance operation area is $37.60 \%$. Among them, the proportion of queuing for small and large vehicles is $36.18 \%$ and $48.26 \%$ respectively. The average queue length of all vehicles is $4.86 \mathrm{pcu}$ and the maximum queue length is 16 pcu. The average queue length of small cars and large cars is $2.41 \mathrm{pcu}$ and $4.87 \mathrm{pcu}$ respectively.

\section{Results}

\subsection{Traffic Conflict Analysis}

The $85 \%$ cumulative frequency curve method is a common method in traffic engineering. According to the velocity distribution generated by the measured cumulative frequency curve, the velocity corresponding to $85 \%$ cumulative frequency is selected as the speed limit value. LI Meng et al. [27] used 85\% cumulative frequency to determine the threshold of traffic conflicts at intersections and divided traffic conflicts into two levels: serious conflict and non-serious conflict. Therefore, in this paper, traffic conflicts are divided into serious conflicts and non-serious conflicts. According to the time headway distribution of the maintenance operation area, Formula (4) is used to determine the corresponding TTC. In this paper, $85 \%$ cumulative frequency is used to divide the severity of traffic conflict. At the same time, the cumulative frequency of $15 \%$ is used to verify the effectiveness of the division of traffic conflict severity. If there is a significant difference between the $85 \%$ cumulative frequency of serious conflicts and the $15 \%$ cumulative frequency of non-serious conflicts, the division of traffic conflicts is unreasonable, otherwise, it is reasonable to divide traffic conflicts into serious and non-serious conflicts. Through statistical analysis of the data, the TTC cumulative frequency distribution is obtained, as shown in Figure 7. In Figure 7, the TTC value corresponding to the $85 \%$ cumulative frequency of serious traffic conflicts is $1.3 \mathrm{~s}$, which is consistent with the TTC value corresponding to the $15 \%$ cumulative frequency of non-serious traffic conflicts, which indicates that it is reasonable to divide the types of traffic conflicts into serious conflicts and general conflicts. When $0<$ TTC $<1.3 \mathrm{~s}$, the traffic conflict is serious conflict; when $1.3 \mathrm{~s}<\mathrm{TTC}$, the traffic conflict is non-serious conflict. The TTC value corresponding to $85 \%$ cumulative frequency is $6.0 \mathrm{~s}$, when $6.0 \mathrm{~s}<T T C$, the traffic conflict is less observed. Therefore, $6.0 \mathrm{~s}$ can be used as the criterion to judge the effectiveness of traffic conflicts, in which, when $6.0 \mathrm{~s}<T T C$, no conflict occurs; when $0<$ TTC $<1.3 \mathrm{~s}$, traffic conflict is serious conflict; when $1.3 \mathrm{~s}<T T C$, traffic conflict is non serious conflict; when $6.0 \mathrm{~s}<T T C$, it is considered that there is no traffic conflict. Therefore, the threshold value of traffic conflict discrimination in maintenance area is set to $6.0 \mathrm{~s}$.

\subsection{Construction of Traffic Conflict Prediction Model}

In the expressway maintenance operation area, due to the need for vehicles to slow down, change lanes, etc., when two or more vehicles are approaching each other at the same time, one party must 
take corresponding risk-avoidance actions, otherwise traffic conflicts will occur. Because the vehicles in different directions of the expressway do not interfere with each other, the traffic conflicts in the expressway maintenance operation area are mainly divided into rear-end collisions and lane-change conflicts [28]. According to the research, it is found that the traffic volume, the mixing rate of large vehicles, the time headway and the speed difference have significant impact on traffic conflicts. Therefore, in this paper, we mainly study the rear-end collisions in the expressway maintenance operation area. The traffic volume, the large vehicle mix-in rate, the time headway and the speed difference are used as parameters, and a traffic conflict prediction model is established based on the TTC model. Through statistical analysis of the maintenance operation area of the Hu-Shan expressway in Lu'an city, Anhui province, it is found that the mean value of traffic conflicts is 75.26 and the variance is 10.6. Using the alpha test to test the dispersion of the data, it is shown that the traffic conflicts have a significant dispersion. Due to the dispersion of traffic conflicts, it is feasible to use a negative binomial distribution for fitting [29]. Combined with the number of traffic conflicts and traffic flow data, the maximum likelihood method is used to estimate the parameters, as shown in Table 3.

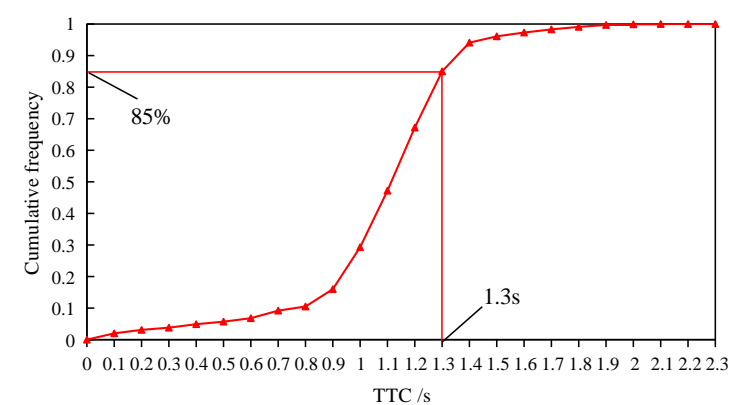

(a)

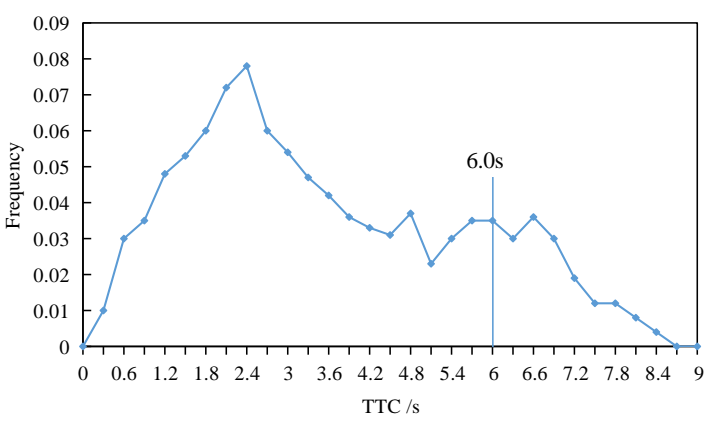

(c)

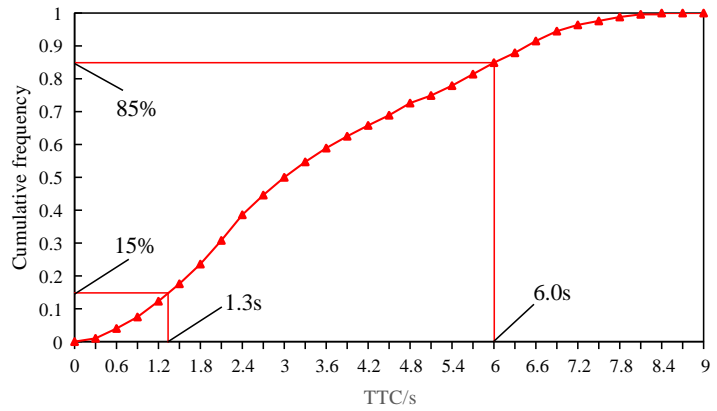

(b)

Figure 7. Distribution of traffic conflicts in maintenance operation areas: (a) serious conflict cumulative frequency distribution; (b) non-serious conflict cumulative frequency distribution; (c) traffic conflict frequency distribution.

Table 3. Estimation of traffic conflict parameters.

\begin{tabular}{ccccccc}
\hline Traffic Conflict & Coefficient $\boldsymbol{\beta}$ & $\begin{array}{c}\text { Standard } \\
\text { Deviation }\end{array}$ & $\boldsymbol{z}$ & $\boldsymbol{p}$ & $\mathbf{9 5 \%}$ Confidence Interval \\
\hline Traffic flow $\left(x_{q}\right)$ & 0.00534 & 0.0006792 & 2.31 & 0.025 & 0.002667 & 0.002929 \\
Large vehicles & 4.889321 & 1.4588371 & 1.03 & 0.033 & 3.007575 & 6.061398 \\
penetration rate $\left(x_{b}\right)$ & 0.019611 & 0.0303476 & 2.51 & 0.028 & 0.438721 & 1.156973 \\
Speed difference $\left(x_{v}\right)$ & -0.58312 & 0.6439872 & -1.41 & 0.000 & -4.567334 & -1.356922 \\
Time headway $\left(h_{t}\right)$ & 2.81207 & 1.3790561 & 3.23 & 0.001 & 1.757953 & 7.163752 \\
Undetermined constant & 0.28673 & 0.0169789 & - & - & 0.004139 & 0.103357 \\
\hline$\alpha$ & & & & & &
\end{tabular}


According to Table $3, p$ values are all less than $0.05, \alpha=0.1868$ and it is not equal to 0 , which indicates that the fitting result using the negative binomial distribution model is correct. The traffic conflict prediction model for the expressway maintenance operation area is:

$$
\begin{gathered}
P_{j}(n) \frac{\Gamma\left(\frac{1}{0.287}+n !\right)}{\Gamma\left(\frac{1}{0.287}\right) \cdot n !}\left(\frac{1}{1+0.287 u_{j}}\right)^{\frac{1}{0.287}} \cdot\left(\frac{u_{j}}{1 / 0.287+u_{j}}\right)^{n} \\
u_{j}=\exp \left(2.812+0.00534 x_{q}+4.889 x_{b}+0.0196 x_{v}-0.583 h_{t}\right)
\end{gathered}
$$

where: $P_{j}(n)$ is the probability of traffic conflicts for the expressway maintenance operation different areas $j ; u_{j}$ is the expectation of traffic conflicts for different areas $j ; n$ indicates the number of traffic conflicts; $x_{q}$ is traffic flow; $x_{b}$ is large vehicles penetration rate; $x_{v}$ is speed difference; $h_{t}$ is time headway.

\subsection{Model Validation}

In order to verify the effectiveness of the traffic conflict prediction model, this paper investigates the traffic data of warning area and upstream transition area of Hu-Shan Expressway. Through the statistical analysis of the traffic flow, the penetration rate of large vehicles, the speed difference and the time headway, as shown in Table 4.

\begin{tabular}{|c|c|c|c|c|}
\hline Variable & $\begin{array}{c}\text { Traffic Flow } \\
x_{q}(\mathrm{pcu} / 30 \mathrm{~min})\end{array}$ & $\begin{array}{c}\text { Large Vehicles } \\
\text { Penetration Rate } x_{b}(\%)\end{array}$ & $\begin{array}{l}\text { Speed Difference } \\
x_{v}(\mathrm{~m} / \mathrm{s})\end{array}$ & $\begin{array}{c}\text { Time headway } \\
h_{t}(\mathrm{~s})\end{array}$ \\
\hline Warning area & 156 & 19.8 & 9.82 & 4.02 \\
\hline upstream transition area & 108 & 26.3 & 5.36 & 3.21 \\
\hline
\end{tabular}

Table 4. Statistical analysis of traffic conflict factors in expressway maintenance area.

This paper uses the MAPE to verify the effectiveness of the traffic conflict prediction model. When the MAPE is less than or equal to $15 \%$, the traffic conflict prediction model has high reliability [30]. In this study, the MAPE calculation formula is as follows:

$$
M A P E=\frac{1}{n} \sum_{m=1}^{n}\left|\frac{C C_{a}^{m}-C C_{p}^{m}}{C C_{a}^{m}}\right|
$$

where: $C C_{a}^{m}$ is number of actual traffic conflicts; $C C_{p}^{m}$ is number of predicted traffic conflicts; and $n$ is number of predicted.

According to the traffic conflict prediction model of expressway maintenance operation area, the total prediction value of traffic conflict in warning area and upstream transition area is calculated, and MAPE is used to compare and analyze the predicted value and measured value. The results are shown in Table 5. According to Table 5, the accuracy of traffic conflict prediction model in expressway maintenance operation area is generally high. The results show that the MAPE of warning area and upstream transition area is $10.8 \%$ and $5.0 \%$.

Table 5. Statistical analysis of traffic conflicts.

\begin{tabular}{cccc}
\hline Conflict Location & Actual Value & Predicted Value & MAPE \\
\hline Warning area & 8.00 & 7.13 & $10.8 \%$ \\
upstream transition area & 7.00 & 6.65 & $5.0 \%$ \\
\hline
\end{tabular}

In addition, a linear regression model was used to fit the predicted traffic conflict and the actual traffic conflict in the warning area and the upstream transition area, respectively. The linear fit is shown in Figure 8. The results show that the warning area and upstream transition area $R^{2}$ are 0.9595 and 0.9587 , the predicted traffic conflicts have a significant correlation with the actual traffic conflicts. Ideally, the slope of the best fit line is 1 [31,32]. In Figure 8, the slopes of the warning zone and the 
upstream transition zone are 0.9758 and 1.0301 , respectively, which is very close to the ideal fit line. Therefore, the traffic conflict prediction model can effectively predict the number of traffic conflicts in the expressway maintenance operation area.

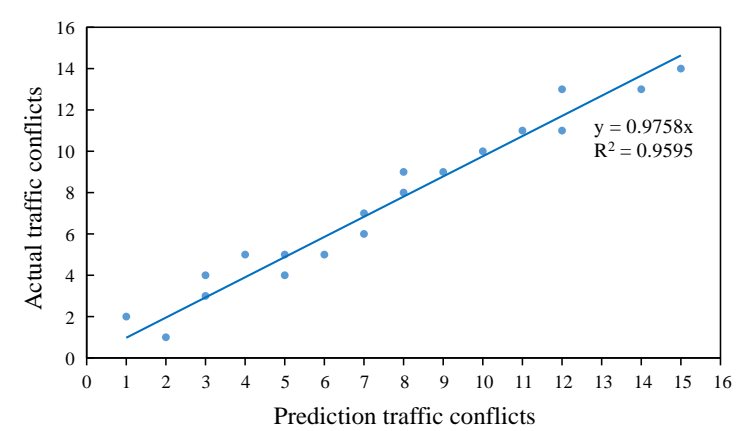

(a)

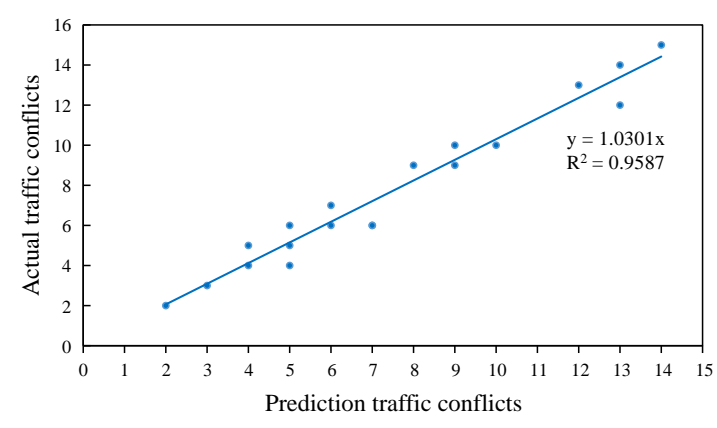

(b)

Figure 8. Validation of traffic conflict prediction model: (a) warning area conflict fitting; (b) upstream transition area conflict fitting.

\section{Conclusions}

In this paper, the two-way four lane expressway outer lane closed maintenance area is taken as the research object to analyze the traffic characteristics of the maintenance area. By improving the TTC model, the severity of traffic conflicts and the threshold for discriminating traffic conflicts in the maintenance area of the expressway are determined. Using the negative binomial distribution model, a traffic conflict prediction model for expressway maintenance operation areas is established. Based on MAPE, the effectiveness of the traffic conflict prediction model is verified. The results show that: when $0<T T C<1.3 \mathrm{~s}$, the traffic conflict is a serious conflict; when $1.3 \mathrm{~s}<T T C$, the traffic conflict is a non-serious conflict; when 6.0s $<T T C$, it is considered that no traffic conflict occurs. Based on the traffic conflict prediction model of the expressway maintenance operation area, The MAPE of warning area and upstream transition area are $10.8 \%$ and $5.0 \%$, respectively. The traffic conflict prediction model has high accuracy, this model can effectively evaluate traffic safety.

One problem that should be emphasized is the traffic conflict prediction model. In this study, only the rear-end traffic conflict was considered, but the lane-change traffic conflict was not considered. At the same time, the traffic conflict prediction model is constructed only for the closed maintenance area of the outer lane of the expressway, and the traffic conflict prediction for other types of maintenance areas of the highway needs further study. In addition, the influence of speed limit value and maintenance operation area length on traffic conflict can be analyzed.

Author Contributions: Writing—original draft, H.G.; writing-review and editing, M.H.; methodology and validation, Y.L.; investigation and data curation, Y.Y. All authors have read and agreed to the published version of the manuscript.

Funding: This research was funded by National Natural Science Foundation of CHINA, grant number 51905224 and grant number 51605197; the Jiangsu Post-Graduate Practice Innovation Project, grant number SJCX18_0749 and in part by the Science and Technology Project of Anhui Transportation Holding Group Company Ltd, grant number GSK-2019-01.

Conflicts of Interest: The authors declare no conflict of interest.

\section{References}

1. Zhang, Q.; Zhang, F.; Liu, J.; Wang, X.; Chen, Q.; Zhao, L.; Tian, L.; Wang, Y. A method for identifying the thin layer using the wavelet transform of density logging data. J. Pet. Sci. Eng. 2018, 160, 433-441. [CrossRef]

2. Xu, W.; Zhao, X.; Chen, Y.; Bian, Y.; Li, H. Research on the Relationship between Dynamic Message Sign Control Strategies and Driving Safety in Freeway Work Zones. J. Adv. Transp. 2018, 2018, 1-19. [CrossRef] 
3. Khattak, A.J.; Council, F.M. Effects of work zone presence on injury and non-injury crashes. Accid. Anal. Prev. 2002, 34, 19-29. [CrossRef]

4. Harb, R.C.; Radwan, E.; Yan, X.; Abdel-Aty, M.; Pande, A. Environmental, Driver and Vehicle Risk Analysis for Freeway Work Zone Crashes. ITE J. 2008, 78, 26-30.

5. Sorock, G.S.; Ranney, T.A.; Lehto, M.R. Motor vehicle crashes in roadway construction work zones: An analysis using narrative text from insurance claims. Accid. Anal. Prev. 1996, 28, 131-138. [CrossRef]

6. Guo, Y.; Sayed, T.; Zaki, M.H.; Liu, P. Safety evaluation of unconventional outside left-turn lane using automated traffic conflict techniques. Can. J. Civ. Eng. 2016, 43, 631-642. [CrossRef]

7. Autey, J.; Sayed, T.; Zaki, M.H. Safety evaluation of right-turn smart channels using automated traffic conflict analysis. Accid. Anal. Prev. 2012, 45, 120-130. [CrossRef]

8. Sacchi, E.; Sayed, T.; Deleur, P. A comparison of collision-based and conflict-based safety evaluations: The case of right-turn smart channels. Accid. Anal. Prev. 2013, 59, 260-266. [CrossRef]

9. Gou, Y.; Liu, P.; Wu, Y.; Yang, M.-L. Traffic Conflict Model Based on Bayesian Multivariate Poisson-lognormal Normal Distribution. J. Chin. Highw. 2018, 31, 101-109.

10. Eustace, D.; Aylo, A.; Mergia, W.Y. Crash frequency analysis of left-side merging and iverging areas on urban freeway segments-A case study of I-75 through downtown Dayton, Ohio. Transp. Res. Part C Emerg. Technol. 2015, 50, 78-85. [CrossRef]

11. Meng, X.H.; Zheng, L.; Bi, H.F.; Guan, Z.Q.; Xu, H.Q. Research on traffic characteristics and traffic conflicts of one-way closed work zone on expressway. Zhongguo Gonglu Xuebao/China J. Highw. Transp. 2013, 26, $140-146$.

12. Kramer, K. Improving work zone safety: Top 10 things you need to know. Transp. Build. 2015, 60, 24-25.

13. Yang, H.; Ozbay, K.; Ozturk, O.; Xie, K. Work zone safety analysis and modeling: A state-of-the-art review. Traffic Inj. Prev. 2015, 14, 387-396. [CrossRef]

14. Zhang, F.; Gambatese, J.; Vahed, A.M. Implementation of Traffic Control Devices on Highway Preservation Projects to Enhance Construction Work Zone Safety. In Proceedings of the Construction Research Congress, Georgia Tech Hotel \& Conference Center, Atlanta, GA, USA, 19-21 May 2014; pp. 1782-1791.

15. Debnath, A.K.; Blackman, R.; Haworth, N. Common hazards and their mitigating measures in work zones: A qualitative study of worker perceptions. Saf. Sci. 2015, 72, 293-301. [CrossRef]

16. Genders, W.; Razavi, S.N. Impact of Connected Vehicle on Work Zone Network Safety through Dynamic Route Guidance. J. Comput. Civ. Eng. 2016, 30, 04015020. [CrossRef]

17. Ceder, A. An application of an optimal traffic control lane closure periods of a two-lane road. J. Adv. Transp. 2010, 34, 173-190. [CrossRef]

18. Garber, N.J.; Zhao, M. Distribution and characteristics of crashes at different work zone locations in Virginia. Transp. Res. Rec. 2002, 1794, 19-25. [CrossRef]

19. Wong, J.M.; Arico, M.C.; Ravani, B. Factors Influencing Injury Severity to Highway Workers in Work Zone Intrusion Accidents. Traffic Inj. Prev. 2011, 12, 31-38. [CrossRef]

20. Venugopal, S.; Tarko, A. Safety Models for Rural Freeway Work Zones. Transp. Res. Rec. J. Transp. Res. Board 2000, 1715, 1-9. [CrossRef]

21. EL-Basyouny, K.; Sayed, T. Safety performance functions using traffic conflicts. Saf. Sci. 2013, 51, 160-164. [CrossRef]

22. Sacchi, E.; Sayed, T. Bayesian Estimation of Conflict-Based Safety Performance Functions. J. Transp. Saf. Secur. 2016, 8, 266-279. [CrossRef]

23. Zhang, X.; Liu, P.; Chen, Y.; Bai, L.; Wang, W. Modeling the Frequency of opposing left-turn conflicts at signalized intersections using generalized linear regression model. Traffic Inj. Prev. 2014, 15, 645-651. [CrossRef] [PubMed]

24. Cai, Y.W.; Xiang, Q.J.; Li, Y.; Ming, X.S. Collision Prediction Model for Interchange Mergring Area Based on Traffic Conflict Technique. In Proceedings of the IEEE International Conference on Intelligent Transportation Engineering, Singapore, 3-5 September 2018; pp. 324-329.

25. Yong, J.; Lei, W.; He, Z.; Xing, Z.; Ruoxi, J. Traffic Conflict Prediction Model for Bottleneck Section of Expressway Construction Area Based on Video Recognition. In Proceedings of the 2019 12th International Conference on Intelligent Computation Technology and Automation (ICICTA), Xiangtan, China, 26-27 October 2019.

26. Guo, Y.-Y.; Liu, P.; Xu, C.-C.; Wu, Y. Safety analysis of right-turn facility at signalized intersection using traffic conflict model. China J. Highw. Transp. 2016, 28, 139-146. 
27. Zheng, L.; Sayed, T.; Essa, M. Validating the bivariate extreme value modeling approach for road safety estimation with different traffic conflict indicators. Accid. Anal. Prev. 2019, 123, 314-323. [CrossRef] [PubMed]

28. Meng, L.; Han, W.X.; Ke, S. Traffic Conflict Identification Technology of Vehicle Intersection Based on Vehicle Video Trajectory Extraction. Procedia Comput. Sci. 2017, 109, 963-968. [CrossRef]

29. Ge, H.; Xia, R.; Sun, H.; Yang, Y.; Huang, M. Construction and Simulation of Rear-End Conflicts Recognition Model Based on Improved TTC Algorithm. IEEE Access 2019, 7, 134763-134771. [CrossRef]

30. Lanping, L. Research on Traffic Conflict Prediction and Safety Evaluation of Freeway Merging Areas; Harbin Institute of Technology: Harbin, China, 2017.

31. Junping, X.; Ma, Y.; Yuan, L. Research on Model Development for Freeway Safety Facilities. Math. Probl. Eng. 2015, 1-6. [CrossRef]

32. Huimin, G.; Yousen, Y. Research on Calculation of Warning Zone Length of Freeway Based on Micro-Simulation Model. IEEE Access 2020, 8, 76532-76540.

(C) 2020 by the authors. Licensee MDPI, Basel, Switzerland. This article is an open access article distributed under the terms and conditions of the Creative Commons Attribution (CC BY) license (http://creativecommons.org/licenses/by/4.0/). 